\title{
CIDE Proteins in Human Health and Disease
}

\author{
Mark Slayton ${ }^{\circledR}$, Abhishek Gupta, Bijinu Balakrishnan and Vishwajeet Puri * \\ Department of Biomedical Sciences and Diabetes Institute, Ohio University Heritage College of Osteopathic \\ Medicine, Athens, OH 45701, USA; slayton@ohio.edu (M.S.); guptaa2@ohio.edu (A.G.); balakrib@ohio.edu (B.B.) \\ * Correspondence: puri@ohio.edu; Tel.: +740-593-2326; Fax: +740-539-1163
}

Received: 19 February 2019; Accepted: 9 March 2019; Published: 13 March 2019

\begin{abstract}
Cell death-Inducing DNA Fragmentation Factor Alpha (DFFA)-like Effector (CIDE) proteins have emerged as lipid droplet-associated proteins that regulate fat metabolism. There are three members in the CIDE protein family-CIDEA, CIDEB, and CIDEC (also known as fat-specific protein 27 (FSP27)). CIDEA and FSP27 are primarily expressed in adipose tissue, while CIDEB is expressed in the liver. Originally, based upon their homology with DNA fragmentation factors, these proteins were identified as apoptotic proteins. However, recent studies have changed the perception of these proteins, redefining them as regulators of lipid droplet dynamics and fat metabolism, which contribute to a healthy metabolic phenotype in humans. Despite various studies in humans and gene-targeting studies in mice, the physiological roles of CIDE proteins remains elusive. This review will summarize the known physiological role and metabolic pathways regulated by the CIDE proteins in human health and disease.
\end{abstract}

Keywords: CIDEA; CIDEB; FSP27; fat metabolism; lipid droplets; adipose; liver

\section{Introduction}

Maintenance of an energy exchange balance is important to all forms of life. CIDE proteins (Cell death-inducing DNA fragmentation factor alpha-like Effector) are an important group of proteins that were originally identified as pro-apoptotic proteins [1,2]. Several years after their discovery and classification as pro-apoptotic proteins, the CIDE proteins were unexpectedly identified as lipid droplet-associated proteins [3-5]. This association is a direct physical interaction with the surface of the lipid droplet, as well as with other lipid droplet proteins, such as perilipin. There are three known CIDE proteins-CIDEA, CIDEB, and CIDEC (herein referred to as FSP27) - which share the homologous CIDE-N domain and the CIDE-C domain, which varies between them. The tissue expression pattern of each CIDE protein differs but is correlative with the fact that they associate with lipid droplets-CIDEA is found primarily in brown adipose (human and mouse) or white adipose tissue (humans only), CIDEB is highly expressed in the liver, and FSP27 is predominately found in white adipose tissue [1,3,5-7]. Disruption of the normal expression of CIDE proteins in mice and humans results in varying metabolic phenotypes between the two species. Several recent studies involving the CIDE proteins have emerged with data from in vitro experiments, as well as in mouse models and in human patients, but the results have been conflicting [6,8-13]. It is now clear that the CIDE proteins play an important role in the regulation of lipid homeostasis.

\section{Role of CIDE Proteins in Apoptosis}

Originally, the CIDE proteins were discovered as apoptotic proteins through a homology search targeting the CIDE-N domain of DNA fragmentation factor 45 (DFF45). The apoptotic pathway is highly regulated and the prevention of its normal activation is linked to several disease states, including cancer [14]. Near the end of the apoptotic pathway, DNA is condensed and then fragmented 
by the nuclease DNA fragmentation factor 40 (DFF40). However, DFF40 is maintained as a complex with DFF45, which inhibits DFF40 until it is cleaved by upstream-activated caspases. The interaction between DFF40 and DFF45 occurs at the N-terminal of both proteins, termed the CIDE-N domain. This domain was utilized in a homology search and other CIDE-N domain-containing proteins were identified [1]. FSP27 (Fat-specific protein, $27 \mathrm{kDa}$ ) was technically the first of the CIDE proteins to be discovered by characterization of cDNA clones derived from highly-expressed genes during adipocyte differentiation [15]. However, it was not until the identification of CIDEA and CIDEB, via homology to the CIDE-N domain, that the alternative names "CIDEC" or "CIDE-3" were used when referring to FSP27 [1,16]. Each of the CIDE proteins share homology with the N-terminal of DFF45 to varying degrees (CIDEA, 39\%; CIDEB, 29\%; FSP27, 38\%) and interact with DFF45 at this conserved domain [1,2]. DFF45 inhibits the apoptotic action of the CIDE proteins through this domain in a manner similar to its interaction with DFF40.

The apoptotic role of CIDE proteins has been primarily demonstrated through ectopic overexpression in mammalian cells or through induced mutations to different amino acid residues of the individual CIDE proteins $[1,16,17]$. Initially, the apoptotic functions of the CIDE proteins were thought to be independent of caspase activation [1]; however, further studies revealed that this function is dependent on caspase-3, caspase-9, and the release of cytochrome c [18,19]. In mice, FSP27 forms a homodimer through interactions at the CIDE-N and CIDE-C domains; additionally, mouse FSP27 forms a heterodimer with CIDEA but this interaction occurs at the CIDE-C domain only $[2,19]$. Recently, CIDE-domain containing proteins (Drep2, Drep4, DFF40, FSP27) were discovered to form head-to-tail helical oligomers, a confirmation that is important for their function [20]. In line with the above observations, both the rate of apoptosis and the level of CIDEA expression were markedly increased in skeletal muscle following an induced burn injury in mice [21], the CIDE-C domain of CIDEB interacts with the hepatitis C non-structural protein 2 (NS2) in the liver to prevent apoptosis [18], and the region of the human genome containing FSP27 (chromosome 3p25) was mutated or absent in several forms of human cancers [16].

For the CIDE proteins to induce apoptosis and fragment DNA, they must localize to the mitochondria $[16,17]$. This notion was challenged by Puri et al. when they identified that FSP27 and CIDEA are highly expressed in adipocytes $[5,22]$ where they are localized to lipid droplets. They found that these proteins were not localized to mitochondria, rather they were associated with lipid droplets and that the endogenous proteins have a crucial role in lipid metabolism $[5,22,23]$. Thus, these proteins were recognized as lipid droplet associated proteins.

A set of elegant studies were performed by Cynthia Smas' group, in which they discovered a dual role for FSP27 in adipocyte metabolism and cell death. FSP27 is highly upregulated during adipogenesis and is dependent on the differentiation of preadipocytes; the FSP27 transcript is downregulated by the presence of tumor necrosis factor- $\alpha$ (TNF- $\alpha)$, but it is upregulated by the presence of insulin [24]. Additionally, this group confirmed that FSP27 did not localize to the mitochondria of COS cells. They overexpressed mouse FSP27 ectopically in 293T and 3T3-L1 cells, which resulted in a cellular morphology indicative of apoptosis; however, there was a lack of DNA fragmentation in 3T3-L1 cells, suggesting that the presence of endogenous lipid droplet machinery inhibits the apoptotic action of FSP27 [24]. Furthermore, in HeLa cells treated with oleic acid, ectopic FSP27 promoted the formation of lipid droplets but did not induce apoptosis [19].

Overall, the role of CIDE proteins in terms of apoptosis has not yet been fully elucidated, but several required factors have been identified. Taken together, these studies indicate that the CIDE proteins are involved in the DNA fragmentation step of the apoptotic cascade; however, there remains much to be discovered in this area of research. Since their discovery as lipid droplet-associated proteins, much of the work regarding the CIDE proteins has been shifted towards investigating their roles in lipid metabolism.

\section{Discovery of CIDE Proteins as Lipid Droplet-Associated Proteins}

FSP27 was discovered 25 years ago as an adipocyte-specific gene that is upregulated during adipogenesis [15,25] and is highly expressed in both white and brown adipose tissues [26]. It was identified 
to be a differentiation-regulated protein activated by peroxisome proliferator-activated receptor- $\gamma$ (PPAR $\gamma)$ [27]. However, the question of FSP27's function remained unsolved until 15 years later, when Puri et al. identified that FSP27 associates with lipid droplets and modulates lipid droplet function for optimal storage of triglycerides by adipocytes [5]. Subsequently, these results were complemented by studies from various other groups [28,29]. A follow-up study showed that the CIDE proteins share significant homology [7] and that CIDEA is also associated with lipid droplets in humans. Thus, the CIDE-domain containing proteins are lipid droplet proteins that define a novel, highly-regulated pathway of triglyceride deposition in human white adipose tissue. Failure of the triglyceride storage pathway results in ectopic lipid accumulation, insulin resistance, and its associated comorbidities in humans. A later study by Ye et al. demonstrated that CIDEB, a liver specific protein, localizes to the endoplasmic reticulum (ER) and lipid droplets, where it promotes the formation of very low-density lipoprotein (VLDL) particles [30]. Overall, these studies suggested a role for CIDE family proteins in lipid metabolism.

\section{CIDE Proteins and Lipid Metabolism}

It appears that depending on the cell type and level of expression, the CIDE proteins localize to additional intracellular organelles. In the case of CIDEA, localization to the Golgi apparatus occurs, while CIDEB is targeted preferentially to the smooth ER. VLDL is transported from the ER in vesicles which contain CIDEB; the biogenesis of these vesicles is also regulated by CIDEB [31-33]. FSP27 is the only CIDE protein that has yet to be observed in the ER, although its presence has been speculated in the ER [34].

Each of the three CIDE proteins localize to the surface of lipid droplets in their respective tissue types (CIDEA, white and brown adipose tissue; CIDEB, liver; FSP27, white adipose tissue) [35-39]. CIDEA directs lipid droplet transfer and fusion in brown and white adipose tissue of mice, as well as in other cell types when expressed ectopically [35,38]. CIDEB was found to promote the storage of lipids in the liver of mice while on a regular diet, but CIDEA and FSP27 increased the size of the droplets under high-fat conditions [36]. Interestingly, in addition to the homology with the CIDE-N domain of DNA fragmentation factor 45, both CIDEA and FSP27 contain four homology domains with perilipin and both localize to the surface of lipid droplets in 3T3-L1 adipocytes [5,7]. Two independent studies demonstrated that FSP27 promotes the enlargement or fusion of lipid droplets via clustering and lipid transfer [37,39]. Perilipin1 interacts with FSP27 during lipid droplet fusion at the CIDE-N domain, but not with CIDEA or CIDEB, suggesting that this interaction is specific within white adipose tissue $[34,40]$. Interestingly, the CIDE-N domain of FSP27 is dispensable for lipid droplet enlargement, but the CIDE-C domain is required [41]. In concurrence with these results, silencing of FSP27 results in a higher number of small lipid droplets, while overexpression increases their size [37,39]. FSP27 expression in the liver is primarily through an alternative transcript, FSP27 $\beta$, which is regulated by cyclic-AMP-responsive-elemental-binding protein $\mathrm{H}$ (CREBH), a transcription factor primarily expressed in the liver [42]. Compared to the main FSP27 isoform, FSP27 $\alpha$, which is transcriptionally regulated by PPAR $\gamma$ and enriched in white adipose tissue, FSP27 $\beta$ contains 10 additional N-terminal amino acids and is involved in the development of hepatic steatosis. Interestingly, although FSP27 $\alpha$ is positively associated with unilocular lipid droplets in white adipocytes, FSP27 $\beta$ was recently found in brown adipocytes and decreases lipid droplet size through a regulatory interaction with CIDEA [43]. These data suggest that the tissue localization of each CIDE protein acts as an additional factor in their function, along with intracellular localization.

As regulators of lipid droplet dynamics, the CIDE proteins are also involved in the rate of intracellular lipolysis. Through the use of RNA interference, Nordström et al. disrupted CIDEA in human preadipocytes and observed an increase in lipolysis and secretion of (TNF- $\alpha$ ) [4]. However, the depletion of CIDEA in adipocytes did not change the rate of lipolysis, demonstrating a difference between the use of preadipocytes and adipocytes [9], while the depletion of FSP27 had a marked increase. It was further demonstrated that FSP27 protects against TNF- $\alpha$-mediated lipolysis, inhibits adipose triglyceride lipase (ATGL) through a protein-protein interaction, and suppresses the ATGL promoter in conjunction with early growth response transcription factor (EGR1) [44-46]. In hepatocytes, 
CIDEB is transcriptionally regulated by PPAR $\gamma$-coactivator-1-alpha (PGC- $1 \alpha$ ) and positively correlated with lipid droplet size, which in turn causes the downregulation of adipose differentiation-related protein (ADRP) [47]. This process can be induced by treatment with human serum and results in enhanced VLDL secretion. These studies demonstrate that the CIDE proteins are important regulators of lipid metabolism by controlling both the size of lipid droplets and the rate of their lipolysis.

\section{Role of CIDE Proteins in Mouse Physiology}

Several knockout studies targeting the CIDE proteins and their metabolic effects have been performed in mice. Mice deficient in Cidea $\left(\mathrm{Cidea}^{-/-}\right.$) have a lean phenotype, higher metabolic rate and body temperature, enhanced lipolysis in brown adipose tissue, and are resistant to diet-induced obesity and diabetes [6]. Mechanistically, this study suggested a direct interaction of Cidea with uncoupling protein 1 (UCP1) to inhibit its thermogenic potential. However, Cidea was later identified not to be localized in the mitochondria. Another potential mechanism was identified in that Cidea interacts with AMP-activated protein kinase (AMPK) $-\beta$ subunit and stimulates ubiquitination-mediated degradation of AMPK [48]. In Cidea-knockout mice, the loss of Cidea-enhanced AMPK stability in brown adipose tissue results in higher fatty acid oxidation and energy expenditure, which contribute to the development of a lean phenotype. Interestingly, the transgenic expression of human Cidea in mouse adipose tissue resulted in a higher body weight than the wild-type littermates, but with improved insulin sensitivity and the maintenance of a healthy obese phenotype [11]. These studies warrant further work to determine whether human and mouse Cidea have opposite roles, or if there is a secondary effect of Cidea knockout that causes increased fatty acid oxidation. A putative explanation could be that enhanced lipolysis in the absence of Cidea would increase availability of FFAs as substrates of fatty acid oxidation.

The tissue-specific expression of Cidea plays a critical role in the healthy or unhealthy phenotype observed in mice. Cidea expression is undetectable in the liver of normal mice but its level is significantly upregulated by treatment with PPAR $\alpha$ and $\gamma$ ligands [49]. Promoter analysis of the Cidea gene revealed that it contains three putative proliferator response elements that are responsive to both PPAR isotypes. Sterol-regulatory-element-binding protein 1c (SREBP1c) mediates the fatty acid synthesis in liver upon insulin stimulation [50]. In mice, liver Cidea expression was trivially reduced upon fasting and restored on refeeding. Furthermore, a sterol regulatory element (SRE) was found in the Cidea promoter region; ChIP analysis confirmed the binding of SREBP1c to the SRE. It was demonstrated that the insulin-mediated effect on Cidea expression was regulated by SERBP1c in the mouse liver. Cidea expression is increased in the hepatocytes of alcohol-induced fatty liver mice and the acetaldehyde concentration in the serum of these mice was significantly increased [51]. Acetaldehyde directly induced the expression of Cidea and was mediated via SERBP1c.

Free fatty acids are well known to induce apoptosis in pancreatic $\beta$-cells [52]. It was found that Cidea expression was significantly elevated during palmitic acid induced apoptosis in mouse pancreatic $\beta$-cells [53]. In addition, silencing of Cidea alleviated palmitic acid-induced apoptosis. The suppression of forkhead box protein O1 (FOXO1) prohibited the upregulation of Cidea in palmitic acid induced apoptosis, suggesting that Cidea is a downstream target of FOXO1.

In addition to adipocytes, liver, and pancreas, Cidea was shown to be highly expressed in sebaceous glands, where the deficiency of Cidea leads to dry hair and hair loss in aged mice [54]. Cidea was found in lactating mammary glands, where it acts as a co-activator of CCAAT/enhancer-binding protein (C/EBP- $\beta$ ) and regulates lipid secretion in milk; the lack of Cidea in the milk of nursing dams can lead to the premature death of their pups [55].

A limited number of studies targeting Cideb in mice have been performed. Cideb is highly expressed in the liver. Apart from the liver, Cideb is expressed in the kidney, stomach, small intestine, colon, and in pancreatic beta cells [10,33]. Cideb localizes to the surface of lipid droplets and the $\mathrm{ER}$, where it promotes the lipidation and maturation of VLDL by interacting with apolipoprotein $\mathrm{B}$ (apoB) [30]. In the small intestine, Cideb plays a crucial role in lipidation of chylomicrons [33]. 
Nascent VLDL particles are transported from the hepatic ER through an ER-specialized vesicle called the VLDL transport vesicle (VTV); knockdown of Cideb in mice has shown to reduce VTV biogenesis significantly [30]. Consequently, mice deficient in Cideb have reduced levels of blood triglycerides (TGs) and non-esterified fatty acids (NEFA) [3]. When fed with a high-fat diet, these mice maintained a lean phenotype and were resistant to hepatic steatosis. They also displayed an increased rate of body metabolism and insulin sensitivity. The resistance to high-fat diet-induced obesity in Cideb-deficient mice was the result of downregulation of fatty acid synthesis through SREBP1c, a crucial factor for TG synthesis. These studies suggested that Cideb might have a negative impact on metabolic health in mice; however, a recent study by Chao et al. manifested that Cideb deficient mice were more vulnerable to dextran sulfate sodium (DSS)-induced ulcerative colitis [56]. DSS induces more oxidative stress in colonocytes and was more deteriorative when the Cideb-deficient mice were fed with a high-fat diet.

Similar to Cidea and Cideb, mouse models of Cidec (herein referred to as Fsp27) have given mixed responses in health and disease. Whole body Fsp27-deficient mice have reduced levels of TGs and smaller lipid droplets in their white adipocytes and were protected from diet-induced obesity [28], resulting in higher glucose uptake rates and improved insulin sensitivity. Furthermore, Fsp27-deficiency led to improved metabolic rates by upregulating genes involved in mitochondrial oxidative metabolism and browning of white adipose tissue [13]. Similarly, silencing of Fsp27 using antisense oligonucleotides in high-fat fed mice and ob/ob mice resulted in decreased visceral adiposity, improved insulin sensitivity, and whole body glycemic control [57]. Srijana et al. found that in mouse adipocytes, TNF $\alpha$-mediated lipolysis is associated with downregulation of Fsp27 [45]. Conversely, lipolysis mediated by isoproterenol was accompanied by upregulation of Fsp27 levels via a delay of the ubiquitin-dependent proteosomal degradation pathway. Complementing these results, Tanaka et al. confirmed that adipose-specific Fsp27 knockout mice were resistant to high fat diet-induced weight gain [58]. These mice had small white adipose mass with multilocular lipid droplets in their adipocytes. The impairment of lipid storage function in adipocytes resulted in ectopic fat accumulation and led to hepatosteatosis and systemic insulin resistance. The above studies suggest that Fsp27 affects whole body insulin sensitivity in a tissue-specific manner.

$\operatorname{PPAR} \gamma$ agonism is used clinically to reduce insulin resistance and improve hyperglycemia associated with type 2 diabetes [59], however, this treatment markedly elevates TG levels in the liver associated with a number of murine models of diabetes or obesity $[13,60]$. Matsusue et al. showed that Fsp27 in the liver of ob/ob mice is a direct target gene of PPAR $\gamma$ to elevate hepatic triglyceride levels [61]. Though there might be intrahepatic insulin resistance in these mice, the whole-body insulin sensitivity was presumably increased due to the therapeutic effect of the PPAR $\gamma$ agonist. Adipocyte-specific disruption of Fsp27 causes hepatosteatosis and insulin resistance in high-fat diet-fed mice, indicating that PPAR $\gamma$ agonist-induced expression in adipose tissue might predominate the effect of fatty liver in terms of whole-body metabolism. A later study showed that Fsp27 $\beta$, but not Fsp27 $\alpha$, is induced in the liver of ob/ob and other mouse models of fatty liver disease in a CREBH-dependent manner [42]. The above contradictory studies warrant further analysis of Fsp27's role in the liver and its tissue-specific role in whole body insulin sensitivity.

Nonetheless, the role of liver-specific Fsp27 expression has consistently been shown to cause fat accumulation in the liver. Hepatocyte-specific disruption of Fsp27 in mice provided protection from the development of alcoholic steatohepatitis [62]. Similar results were obtained when mice were treated with adenovirus-Fsp27shRNA. Therefore, upregulation of Fsp27 in the liver contributes to alcohol-induced liver damage. Fsp27, presumably Fsp27 $\alpha$, has been shown to play a crucial role in the formation of unilocular large lipid droplets in white adipocytes. Fsp27 $\beta$ isoform, besides the liver, is expressed in the brown adipose tissue but in a CREBH-independent manner [43]. Fsp27 $\beta$ and Cidea co-operatively form small multilocular lipid droplets, which is an advantageous morphology for the transport of FFA to mitochondria for oxidation in brown adipocytes. Since CREBH is not expressed in brown adipose tissue, the mechanisms responsible for regulating the expression of Fsp27 $\beta$ in brown adipose tissue remain unclear. 
Studies on fasting mice showed that Fsp27 expression in the liver is initially increased, however in the later stages of fasting, the expression was decreased [63]. This early response of Fsp27 was contributed to by the PKA (protein kinase A)-CREB-CRTC2 (CREB-regulated transcription coactivator 2) signaling pathway. This study is in line with the role of Fsp27 in the regulation of lipolysis [44,46], since during the late stages of fasting, lipolysis is increased to keep up with the supply of fatty acids and energy production.

An exciting role of Fsp27 in osteoarthritis has been identified recently [64]. High-fat diet-induced osteoarthritis models revealed that FFA released from lipid droplets exerted the lipotoxic effect observed in articular chondrocytes. Articular chondrocytes were rescued from FFA-induced lipotoxicity by FFA sequestration, which was mediated by protein kinase casein kinase 2 (PKCK2), a six-transmembrane protein of prostate 2 (STAMP2) and Fsp27.

Cidea/Fsp27 double-deficient mice exhibited a drastic reduction in lipid storage capabilities, reflected by smaller lipid droplets in white adipose tissue compared to Cidea or Fsp27 single-deficient mice $[38,65]$. In these studies, the Fsp27-deficient mice lost the ability to store lipids in their adipose tissue, which resulted in ectopic storage of fat in the liver and insulin resistance. Conversely, Cidea/Fsp27 double-deficient mice did not have ectopic storage of lipids in the liver and exhibited improved insulin sensitivity. Fsp27-deficient mice were mated with leptin $(\mathrm{ob} / \mathrm{ob})$ knockout mice to obtain double deficient $\mathrm{ob} / \mathrm{ob} / \mathrm{Fsp} 27^{-/-}$mice [65]. These mice showed significantly less body weight compared to the littermate controls due to a lower accumulation of both visceral and subcutaneous fat, as well as a substantial reduction in adipose inflammation and increased adiponectin level. Plasma glycerol levels in ob/ob/Fsp27 $7^{-/}$mice were drastically elevated compared to littermate controls due to increased lipolysis; these mice also developed fatty liver and insulin resistance. Overall, these studies demonstrated that a lack of Fsp27 expression in mice significantly reduces the lipid storage capabilities of adipose tissue and results in ectopic fat deposition that leads to hepatic steatosis and insulin resistance.

In conclusion, the metabolic effects observed in various mouse models of CIDE proteins have not been consistent with their positive versus negative role in health and disease (Figure 1). It could be that complete knockout or exogenous expression of these proteins produces secondary effects in mice that contributes to the outcomes observed. Furthermore, the tissue-specific expression of CIDE proteins appears to have differential effects on whole-body metabolism.

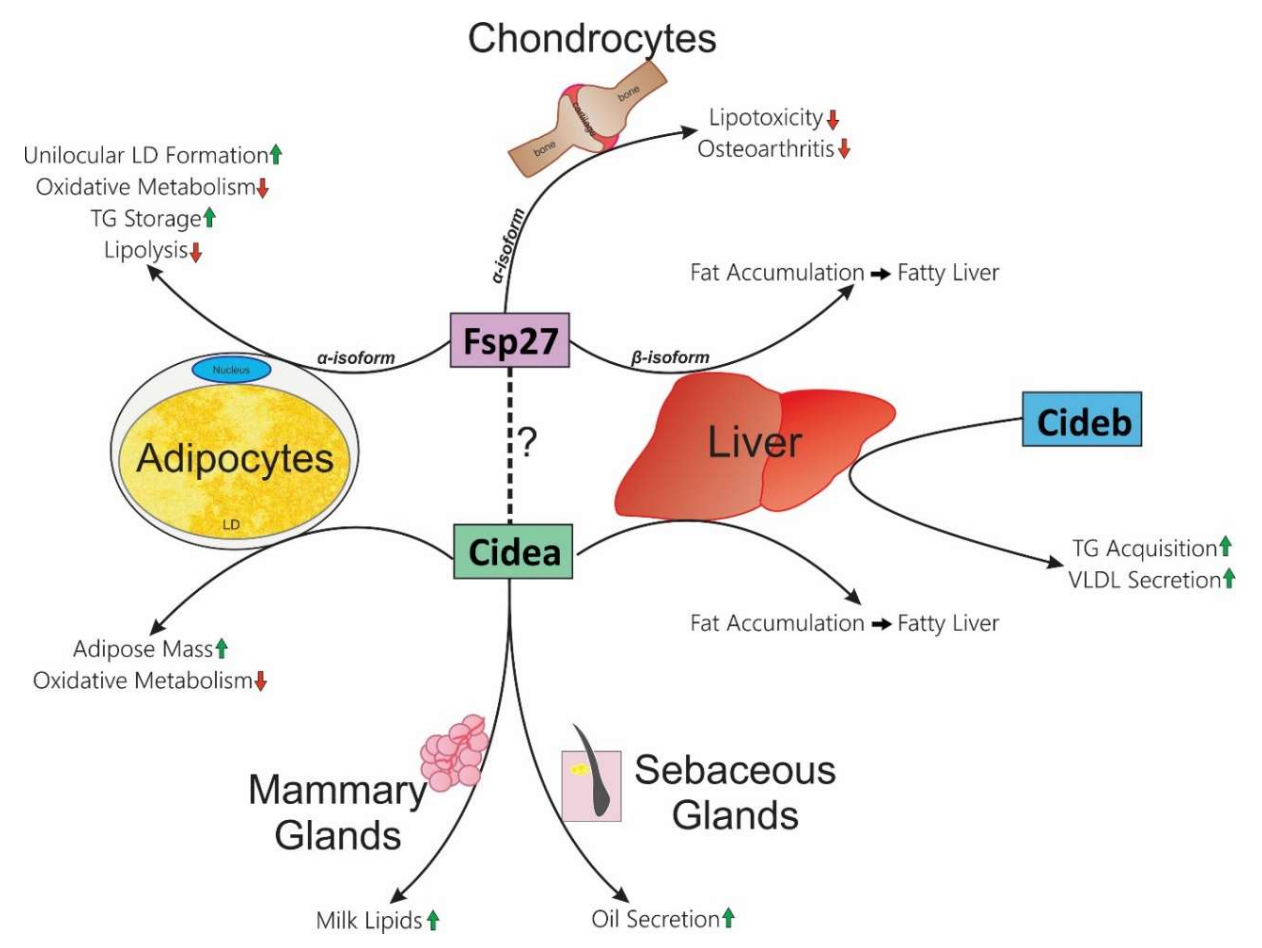

Figure 1. Tissue-specific functions of CIDE proteins in mice. Each CIDE protein is indicated with colored rectangles. The known functions within respective tissues are listed at the end of arrows which 
pass by them (Cidea: adipocytes, liver, mammary glands, and sebaceous glands; Cideb: liver; Fsp27: adipocytes, chondrocytes, and liver). Green up-arrows indicate an increase; red down-arrows indicate a decrease. Dotted line indicates that Fsp27 and Cidea could form a heteromeric complex, which could be essential for one or more of their functions.

\section{Role of CIDE Proteins in Human Metabolic Health}

Gene association studies (also known as polymorphism studies) focus on variations amongst specific genes and alleles and their association with disease. According to the National Center for Biotechnology Information (NCBI), around 6658 single nucleotide polymorphisms (SNPs) have been found in the human CIDEA genes, although not all of them are associated with the disease phenotype. Worldwide clinical studies report around 66 SNPs in CIDEA that are associated with human diseases (NCBI ClinVar). Of these 66 SNPs, 24 are deletions, whereas 42 are duplications.

The human CIDEA gene is located on chromosome 18 (18p11) and spans around 23.22 kilobases $(\mathrm{kb})$ in length, with 4 introns and 5 exons. Linkage studies performed to assess the association of body mass index reported the association of this locus with the development of obesity [66]. Another independent study performed by Parker et al. determined that the chromosome 18p11 region is positively associated with type 2 diabetes and obesity [67].

A study by Dahlman et al. revealed the association of a CIDEA polymorphism (V115F) with the occurrence of obesity (see Figure 2) [68]. This study was performed in two different Swedish cohorts comprising men and women categorized into non-obese and obese populations. Characterization of the V115F polymorphism revealed six different polymorphic sites in obese individuals, as compared to the non-obese counterparts. However, only one SNP $(C 19878 \mathrm{G} \rightarrow \mathrm{T})$ was found in the coding region and was responsible for creating the V115F mutation. The study concluded that this polymorphism was positively and significantly associated with obesity and reduced basal metabolic rate. An additional study comprised of 272 male Japanese individuals identified the same polymorphism (V115F) [69]. This study assessed the association of this amino acid substitution) with the prevalence of metabolic syndrome between two groups-VV vs. VF + FF (valine, V; phenylanaline, F). They concluded that VF + FF individuals have higher abdominal obesity, high fasting plasma glucose levels, and an increased risk of metabolic syndrome. Similarly, an independent study in a Chinese cohort clarified the positive association of the CIDEA V115F polymorphism with the risk of metabolic syndrome [8].

Another study conducted by $\mathrm{Wu}$ et al. studied the association of five polymorphisms in the CIDEA gene with obesity in the Chinese population [70]. The polymorphisms included were rs1154588/V115F, rs4796955, rs8092502, rs12962340, and rs7230480. Individuals with the rs1154588/V115F, rs4796955, rs8092502, or rs7230480 polymorphism had around 1.4-fold increased risk of developing obesity. Further, the study concluded that individuals with both rs1154588/V115F and rs4796955 polymorphisms were more prone to developing diabetes. In addition to the above SNPs, the association of rs2479 and rs1053239 SNPs in CIDEA with rapid progression of high blood pressure have been reported [70]. The individuals with rs2479 SNP are more prone to having elevated fasting blood glucose levels along with high triglyceride levels. Overall, the above polymorphism studies unequivocally showed the positive association of CIDEA with healthy metabolic phenotypes in humans.

Functionally, CIDEA was identified as a lipid droplet-associated protein, and its expression was in consonance with insulin sensitivity in obese humans [7]. In this study, Puri et al. confirmed the PPAR $\gamma$-mediated regulation of CIDEA expression in white adipose tissue samples from obese individuals undergoing gastric-bypass surgery (see Figure 2). CIDEA expression in white adipose tissue of obese human subjects was determined and found to correlate positively with whole-body insulin sensitivity independent of gender or BMI. Diet-induced weight loss showed a positive correlation of CIDEA and metabolic health [71,72]. Interestingly, changes in adipose tissue CIDEA mRNA levels paralleled variations in insulin sensitivity independently of the change in body mass index [72]. CIDEA was up-regulated in the adipose tissue of individuals with successful long-term 
insulin resistance relapse and not in adipose tissue of unsuccessful individuals, suggesting a beneficial role of adipose tissue CIDEA in long term glucose homeostasis, independently of weight variation.

Similar to CIDEA, a specific SNP in FSP27 has also been shown to be associated with the causation of metabolic syndrome. The SNP $(\mathrm{G} \rightarrow \mathrm{T})$ occurs at nucleotide position 556 within exon 6 of FSP27 and inserts a premature stop codon (TAA), resulting in a non-sense mutation (E186X) that disrupts the CIDE-C domain. This mutation has been reported to be associated with partial lipodystrophy and insulin resistance in a female patient (see Figure 2) [12].

Homeostatic Model Assessment for Insulin Resistance (HOMA-IR; an index for assessment of insulin sensitivity) is positively correlated with FSP27 expression in BMI-matched obese individuals [7]. The level of FSP27 in adipose tissue reduces with the development of obesity and is negatively correlated with TNF- $\alpha$ [73]. Complimentarily, FSP27 expression was found to be decreased with increasing BMI, fasting glucose, fasting insulin, and HOMA-IR [74]. The latter study elegantly showed that bariatric surgery-induced weight loss caused an increase in FSP27 expression in subcutaneous adipose tissue in parallel to adipogenic and mitochondrial genes. Interestingly, PLIN1 levels were also increased. The latter observation was in line with a positive correlation of adipose PLIN1 expression with insulin sensitivity in obese humans [7]. Various other studies have suggested the role of PLIN1 in metabolic health in humans [75], indicating a concerted effort of these lipid droplet-associated proteins in maintaining insulin sensitivity.

FSP27 regulates lipid droplet dynamics and lipolysis in adipocytes through regulation of the catalytic capacity [44], as well as through transcriptional regulation of adipose triglyceride lipase (ATGL), the rate-limiting enzyme in lipolysis [46]. These studies demonstrated a mutual relationship between FSP27 and ATGL in regulating lipolysis, triglyceride accumulation, and insulin signaling in human adipocytes. As a proof of concept, the former study showed that FSP27 protects human adipocytes from FFA-mediated insulin resistance [44], thus highlighting the mechanistic role of FSP27 in maintaining insulin sensitivity, potentially by maintaining an optimal balance of energy storage and breakdown.

Recently, the role of FSP27 in human growth hormone (GH)-induced diabetes was elucidated [76]. GH-induced lipolysis in human subjects is tightly associated with an acute reduction in CIDEC expression in subcutaneous adipose tissue. Furthermore, the study described that GH-induced lipolysis is mediated via Mitogen-activated protein kinase kinase/Extracellular signal-regulated kinase (MEK/ERK) activation, which suppresses PPAR $\gamma$ transcriptional activity (see Figure 2) with a feedback loop, by which FSP27 protects PPAR $\gamma$ from being phosphorylated at $\operatorname{Ser}^{273}$. PPAR $\gamma \operatorname{Ser}^{273}$ phosphorylation has been linked with the development of insulin resistance [77-79]. In human adipocytes exposed to GH, exogenous FSP27 stabilized PPAR $\gamma$ in the nucleus by inhibiting its phosphorylation at $\operatorname{Ser}^{273}$ [76]. Another complimentary study in mice and mouse cell lines showed that GH modulation of FSP27 expression is mediated through activation of both MEK/ERK and STAT5 dependent intracellular signaling, whereby, GH-induced MEK/ERK pathway has a predominating role in PPAR $\gamma$ inactivation [80]. Overall, these studies deciphered part of the molecular mechanism by which FSP27 regulates insulin sensitivity.

Taken together, the various mouse models have shown contradictory results on the role of CIDE proteins in whole-body metabolic phenotype. On the contrary, all of the human studies published to date unequivocally show a negative association of CIDEA and FSP27 with the pathogenesis and pathophysiology of metabolic disease in humans (Figure 2), giving prominence to their role in improving the metabolic health of humans. 


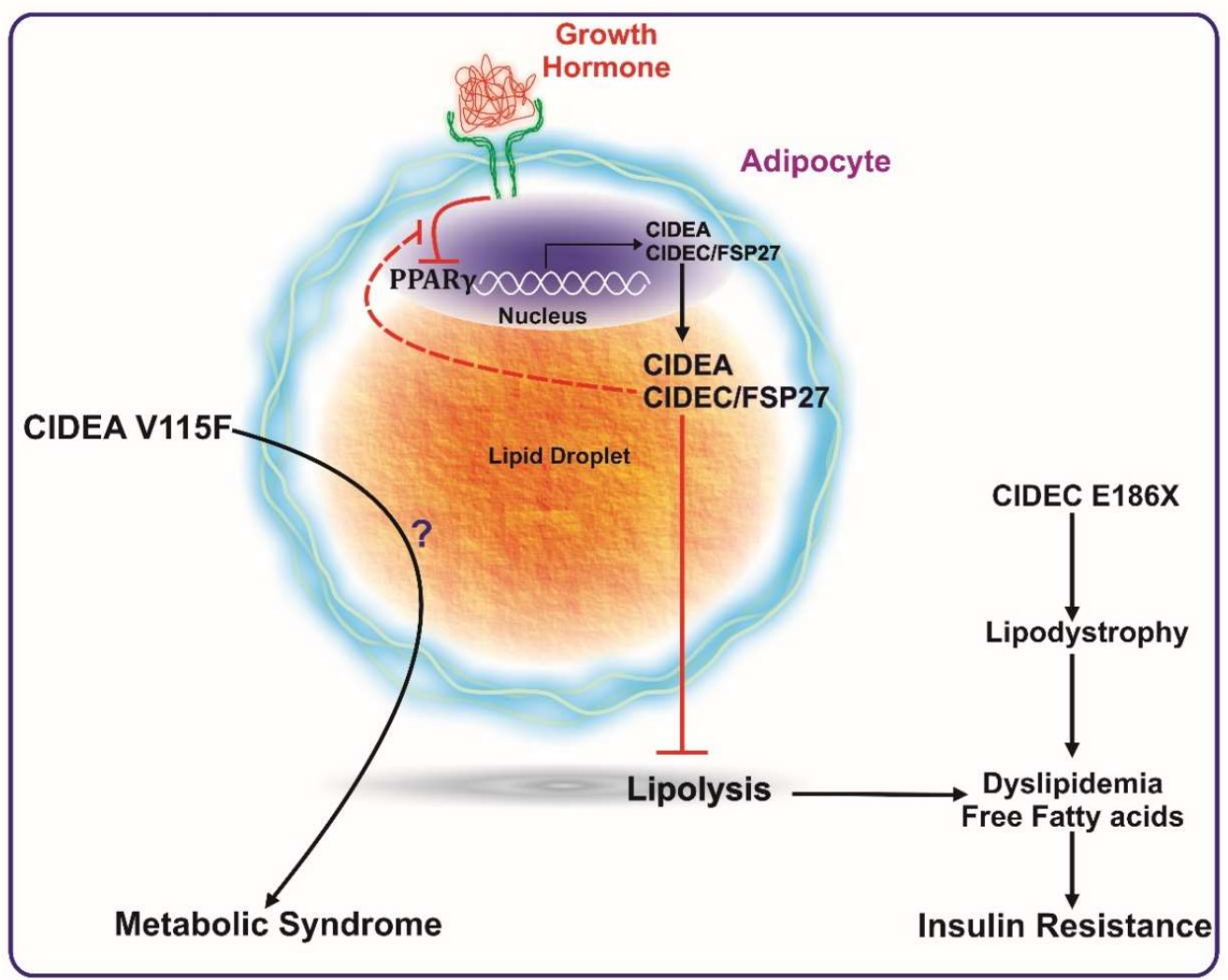

Figure 2. CIDEA and CIDEC/FSP27 are transcriptionally activated by PPAR $\gamma$ expression. CIDEA and FSP27 bind to lipid droplets and inhibit lipolysis. Reduction in PPAR $\gamma$ activation (such as by growth hormone) reduces the expression levels of these proteins, which ultimately causes enhanced lipolysis, leading to a higher concentration of systemic free fatty acids. The increase in serum free fatty acids culminates in insulin resistance. A mutation in FSP27 (CIDEC E186X) causes lipodystrophy and insulin-resistant type 2 diabetes. The V115F polymorphism in CIDEA is reported to be positively associated with metabolic syndrome. Excess growth hormone levels (such as in acromegaly patients) inactivate PPAR $\gamma$ causing reduced expression of FSP27. FSP27 protects against GH-mediated destabilization of PPAR $\gamma$ to maintain insulin sensitivity.

\section{Concluding Remarks}

The studies reported here indicate that the CIDE proteins are important regulators of fat metabolism. The functionality of each CIDE protein appears to depend highly on intracellular localization and tissue expression. It is currently unclear as to why there is a discrepancy between the metabolic phenotypes from studies targeting CIDE proteins in mice versus humans. However, the studies agree that the CIDE proteins are involved in lipid storage. Furthermore, the metabolic consequences of tissue-specific CIDE protein knockout appears to be different than that of whole-body knockouts. The human studies published to-date unequivocally show a negative association of CIDEA and FSP27 with the pathogenesis and pathophysiology of metabolic disease in humans. Further work is required to elucidate the mechanism by which the expression of each CIDE protein contributes to the regulation of insulin sensitivity or resistance and to examine their use as a potential therapeutic.

Acknowledgments: We thank Vishva Sharma for helpful comments and discussion.

Conflicts of Interest: The authors declare no conflict of interest. 


\section{References}

1. Inohara, N.; Koseki, T.; Chen, S.; Wu, X.; Núñez, G. CIDE, a novel family of cell death activators with homology to the $45 \mathrm{kDa}$ subunit of the DNA fragmentation factor. EMBO J. 1998, 17, 2526-2533. [CrossRef]

2. Lugovskoy, A.A.; Zhou, P.; Chou, J.J.; McCarty, J.S.; Li, P.; Wagner, G. Solution Structure of the CIDE-N Domain of CIDE-B and a Model for CIDE-N/CIDE-N Interactions in the DNA Fragmentation Pathway of Apoptosis. Cell 1999, 99, 747-755. [CrossRef]

3. Li, J.Z.; Ye, J.; Xue, B.; Qi, J.; Zhang, J.; Zhou, Z.; Li, Q.; Wen, Z.; Li, P. Cideb regulates diet-induced obesity, liver steatosis, and insulin sensitivity by controlling lipogenesis and fatty acid oxidation. Diabetes 2007, 56, 2523-2532. [CrossRef]

4. Nordström, E.A.; Rydén, M.; Backlund, E.C.; Dahlman, I.; Kaaman, M.; Blomqvist, L.; Cannon, B.; Nedergaard, J.; Arner, P. A Human-Specific Role of Cell Death-Inducing DFFA (DNA Fragmentation Factor- $\alpha$ )-Like Effector A (CIDEA) in Adipocyte Lipolysis and Obesity. Diabetes 2005, 54, 1726-1734. [CrossRef]

5. Puri, V.; Konda, S.; Ranjit, S.; Aouadi, M.; Chawla, A.; Chouinard, M.; Chakladar, A.; Czech, M.P. Fat-specific Protein 27, a Novel Lipid Droplet Protein That Enhances Triglyceride Storage. J. Biol. Chem. 2007, 282, 34213-34218. [CrossRef]

6. Zhou, Z.; Yon Toh, S.; Chen, Z.; Guo, K.; Peng Ng, C.; Ponniah, S.; Lin, S.-C.; Hong, W.; Li, P. Cidea-deficient mice have lean phenotype and are resistant to obesity. Nat. Genet. 2003, 35, 49. [CrossRef]

7. Puri, V.; Ranjit, S.; Konda, S.; Nicoloro, S.M.C.; Straubhaar, J.; Chawla, A.; Chouinard, M.; Lin, C.; Burkart, A.; Corvera, S.; et al. Cidea is associated with lipid droplets and insulin sensitivity in humans. Proc. Natl. Acad. Sci. USA 2008, 105, 7833-7838. [CrossRef]

8. Zhang, L.; Dai, Y.; Bian, L.; Wang, W.; Wang, W.; Muramatsu, M.; Hua, Q. Association of the cell death-inducing DNA fragmentation factor alpha-like effector A (CIDEA) gene V115F (G/T) polymorphism with phenotypes of metabolic syndrome in a Chinese population. Diabetes Res. Clin. Pract. 2011, 91, $233-238$. [CrossRef]

9. Ito, M.; Nagasawa, M.; Hara, T.; Ide, T.; Murakami, K. Differential roles of CIDEA and CIDEC in insulin-induced anti-apoptosis and lipid droplet formation in human adipocytes. J. Lipid Res. 2010, 51, 1676-1684. [CrossRef]

10. Li, H.; Song, Y.; Zhang, L.J.; Li, F.F.; Gu, Y.; Zhang, J.; Dong, W.P.; Xue, L.; Zhang, L.Y.; Liu, F.; et al. Cell death-inducing DFF45-like effector $\mathrm{b}$ (Cideb) is present in pancreatic beta-cells and involved in palmitate induced beta-cell apoptosis. Diabetes Metab. Res. Rev. 2012, 28, 145-155. [CrossRef]

11. Abreu-Vieira, G.; Fischer, A.W.; Mattsson, C.; de Jong, J.M.A.; Shabalina, I.G.; Rydén, M.; Laurencikiene, J.; Arner, P.; Cannon, B.; Nedergaard, J.; et al. Cidea improves the metabolic profile through expansion of adipose tissue. Nat. Commun. 2015, 6, 7433. [CrossRef]

12. Rubio-Cabezas, O.; Puri, V.; Murano, I.; Saudek, V.; Semple, R.K.; Dash, S.; Hyden, C.S.S.; Bottomley, W.; Vigouroux, C.; Magré, J.; et al. Partial lipodystrophy and insulin resistant diabetes in a patient with a homozygous nonsense mutation in CIDEC. EMBO Mol. Med. 2009, 1, 280-287. [CrossRef]

13. Toh, S.Y.; Gong, J.; Du, G.; Li, J.Z.; Yang, S.; Ye, J.; Yao, H.; Zhang, Y.; Xue, B.; Li, Q.; et al. Up-regulation of mitochondrial activity and acquirement of brown adipose tissue-like property in the white adipose tissue of fsp27 deficient mice. PLoS ONE 2008, 3, e2890. [CrossRef]

14. Thompson, C.B. Apoptosis in the pathogenesis and treatment of disease. Science 1995, 267, $1456-1462$. [CrossRef]

15. Chapman, A.B.; Knight, D.M.; Dieckmann, B.S.; Ringold, G.M. Analysis of gene expression during differentiation of adipogenic cells in culture and hormonal control of the developmental program. J. Biol. Chem. 1984, 259, 15548-15555.

16. Liang, L.; Zhao, M.; Xu, Z.; Yokoyama, K.K.; Li, T. Molecular cloning and characterization of CIDE-3, a novel member of the cell-death-inducing DNA-fragmentation-factor (DFF45)-like effector family. Biochem. J. 2003, 370, 195-203. [CrossRef]

17. Chen, Z.; Guo, K.; Toh, S.Y.; Zhou, Z.; Li, P. Mitochondria Localization and Dimerization Are Required for CIDE-B to Induce Apoptosis. J. Biol. Chem. 2000, 275, 22619-22622. [CrossRef] 
18. Erdtmann, L.; Franck, N.; Lerat, H.; Seyec, J.L.; Gilot, D.; Cannie, I.; Gripon, P.; Hibner, U.; Guguen-Guillouzo, C. The Hepatitis C Virus NS2 Protein Is an Inhibitor of CIDE-B-induced Apoptosis. J. Biol. Chem. 2003, 278, 18256-18264. [CrossRef]

19. Liu, K.; Zhou, S.; Kim, J.-Y.; Tillison, K.; Majors, D.; Rearick, D.; Lee, J.H.; Fernandez-Boyanapalli, R.F.; Barricklow, K.; Houston, M.S.; et al. Functional analysis of FSP27 protein regions for lipid droplet localization, caspase-dependent apoptosis, and dimerization with CIDEA. Am. J. Physiol. Endocrinol. Metab. 2009, 297, E1395-E1413. [CrossRef]

20. Choi, J.Y.; Qiao, Q.; Hong, S.-H.; Kim, C.M.; Jeong, J.-H.; Kim, Y.-G.; Jung, Y.-K.; Wu, H.; Park, H.H. CIDE domains form functionally important higher-order assemblies for DNA fragmentation. Proc. Natl. Acad. Sci. USA 2017, 114, 7361-7366. [CrossRef]

21. Duan, H.; Chai, J.; Sheng, Z.; Yao, Y.; Yin, H.; Liang, L.; Shen, C.; Lin, J. Effect of burn injury on apoptosis and expression of apoptosis-related genes/proteins in skeletal muscles of rats. Apoptosis 2009, 14, 52-65. [CrossRef]

22. Puri, V.; Virbasius, J.V.; Guilherme, A.; Czech, M.P. RNAi screens reveal novel metabolic regulators: RIP140, MAP4k4 and the lipid droplet associated fat specific protein (FSP) 27. Acta Physiol. 2008, 192, 103-115. [CrossRef] [PubMed]

23. Brasaemle, D.L.; Dolios, G.; Shapiro, L.; Wang, R. Proteomic Analysis of Proteins Associated with Lipid Droplets of Basal and Lipolytically Stimulated 3T3-L1 Adipocytes. J. Biol. Chem. 2004, 279, 46835-46842. [CrossRef] [PubMed]

24. Kim, J.Y.; Liu, K.; Zhou, S.; Tillison, K.; Wu, Y.; Smas, C.M. Assessment of fat-specific protein 27 in the adipocyte lineage suggests a dual role for FSP27 in adipocyte metabolism and cell death. Am. J. Physiol. Endocrinol. Metab. 2008, 294, E654-E667. [CrossRef] [PubMed]

25. Danesch, U.; Hoeck, W.; Ringold, G.M. Cloning and transcriptional regulation of a novel adipocyte-specific gene, FSP27. CAAT-enhancer-binding protein (C/EBP) and C/EBP-like proteins interact with sequences required for differentiation-dependent expression. J. Biol. Chem. 1992, 267, 7185-7193.

26. Su, A.I.; Cooke, M.P.; Ching, K.A.; Hakak, Y.; Walker, J.R.; Wiltshire, T.; Orth, A.P.; Vega, R.G.; Sapinoso, L.M.; Moqrich, A.; et al. Large-scale analysis of the human and mouse transcriptomes. Proc. Natl. Acad. Sci. USA 2002, 99, 4465-4470. [CrossRef]

27. Yu, S.; Matsusue, K.; Kashireddy, P.; Cao, W.-Q.; Yeldandi, V.; Yeldandi, A.V.; Rao, M.S.; Gonzalez, F.J.; Reddy, J.K. Adipocyte-specific gene expression and adipogenic steatosis in the mouse liver due to peroxisome proliferator-activated receptor gamma1 (PPARgamma1) overexpression. J. Biol. Chem. 2003, 278, 498-505. [CrossRef]

28. Nishino, N.; Tamori, Y.; Tateya, S.; Kawaguchi, T.; Shibakusa, T.; Mizunoya, W.; Inoue, K.; Kitazawa, R.; Kitazawa, S.; Matsuki, Y.; et al. FSP27 contributes to efficient energy storage in murine white adipocytes by promoting the formation of unilocular lipid droplets. J. Clin. Investig. 2008, 118, 2808-2821. [CrossRef]

29. Keller, P.; Petrie, J.T.; Rose, P.D.; Gerin, I.; Wright, W.S.; Chiang, S.-H.; Nielsen, A.R.; Fischer, C.P.; Pedersen, B.K.; MacDougald, O.A. Fat-specific Protein 27 Regulates Storage of Triacylglycerol. J. Biol. Chem. 2008, 283, 14355-14365. [CrossRef]

30. Ye, J.; Li, J.Z.; Liu, Y.; Li, X.; Yang, T.; Ma, X.; Li, Q.; Yao, Z.; Li, P. Cideb, an ER- and Lipid Droplet-Associated Protein, Mediates VLDL Lipidation and Maturation by Interacting with Apolipoprotein B. Cell Metab. 2009, 9, 177-190. [CrossRef]

31. Li, X.; Ye, J.; Zhou, L.; Gu, W.; Fisher, E.A.; Li, P. Opposing roles of cell death-inducing DFF45-like effector B and perilipin 2 in controlling hepatic VLDL lipidation. J. Lipid Res. 2012, 53, 1877-1889. [CrossRef]

32. Tiwari, S.; Siddiqi, S.; Siddiqi, S.A. CideB protein is required for the biogenesis of very low density lipoprotein (VLDL) transport vesicle. J. Biol. Chem. 2013, 288, 5157-5165. [CrossRef] [PubMed]

33. Zhang, L.-J.; Wang, C.; Yuan, Y.; Wang, H.; Wu, J.; Liu, F.; Li, L.; Gao, X.; Zhao, Y.-L.; Hu, P.-Z.; et al. Cideb facilitates the lipidation of chylomicrons in the small intestine. J. Lipid Res. 2014, 55, 1279-1287. [CrossRef] [PubMed]

34. Grahn, T.H.M.; Zhang, Y.; Lee, M.-J.; Sommer, A.G.; Mostoslavsky, G.; Fried, S.K.; Greenberg, A.S.; Puri, V. FSP27 and PLIN1 interaction promotes the formation of large lipid droplets in human adipocytes. Biochem. Biophys. Res. Commun. 2013, 432, 296-301. [CrossRef] [PubMed]

35. Christianson, J.L.; Boutet, E.; Puri, V.; Chawla, A.; Czech, M.P. Identification of the lipid droplet targeting domain of the Cidea protein. J. Lipid Res. 2010, 51, 3455-3462. [CrossRef] 
36. Xu, W.; Wu, L.; Yu, M.; Chen, F.-J.; Arshad, M.; Xia, X.; Ren, H.; Yu, J.; Xu, L.; Xu, D.; et al. Differential Roles of CIDE Proteins in Promoting Lipid Droplet Fusion and Growth in Subpopulations of Hepatocytes. J. Biol. Chem. 2016. [CrossRef] [PubMed]

37. Gong, J.; Sun, Z.; Wu, L.; Xu, W.; Schieber, N.; Xu, D.; Shui, G.; Yang, H.; Parton, R.G.; Li, P. Fsp27 promotes lipid droplet growth by lipid exchange and transfer at lipid droplet contact sites. J. Cell Biol. 2011, 195, 953-963. [CrossRef] [PubMed]

38. Wu, L.; Zhou, L.; Chen, C.; Gong, J.; Xu, L.; Ye, J.; Li, D.; Li, P. Cidea controls lipid droplet fusion and lipid storage in brown and white adipose tissue. Sci. China Life Sci. 2014, 57, 107-116. [CrossRef] [PubMed]

39. Jambunathan, S.; Yin, J.; Khan, W.; Tamori, Y.; Puri, V. FSP27 Promotes Lipid Droplet Clustering and Then Fusion to Regulate Triglyceride Accumulation. PLoS ONE 2011, 6, e28614. [CrossRef]

40. Sun, Z.; Gong, J.; Wu, H.; Xu, W.; Wu, L.; Xu, D.; Gao, J.; Wu, J.; Yang, H.; Yang, M.; et al. Perilipin1 promotes unilocular lipid droplet formation through the activation of Fsp27 in adipocytes. Nat. Commun. 2013, 4, 1594. [CrossRef]

41. Tamori, Y.; Tateya, S.; Ijuin, T.; Nishimoto, Y.; Nakajima, S.; Ogawa, W. Negatively-charged residues in the polar carboxy-terminal region in FSP27 are indispensable for expanding lipid droplets. FEBS Lett. 2016, 590, 750-759. [CrossRef] [PubMed]

42. Xu, X.; Park, J.-G.; So, J.-S.; Lee, A.-H. Transcriptional activation of Fsp27 by the liver-enriched transcription factor CREBH promotes lipid droplet growth and hepatic steatosis. Hepatology 2015, 61, 857-869. [CrossRef] [PubMed]

43. Nishimoto, Y.; Nakajima, S.; Tateya, S.; Saito, M.; Ogawa, W.; Tamori, Y. Cell death-inducing DNA fragmentation factor A-like effector A and fat-specific protein $27 \beta$ coordinately control lipid droplet size in brown adipocytes. J. Biol. Chem. 2017. [CrossRef] [PubMed]

44. Grahn, T.H.M.; Kaur, R.; Yin, J.; Schweiger, M.; Sharma, V.M.; Lee, M.-J.; Ido, Y.; Smas, C.M.; Zechner, R.; Lass, A.; et al. FSP27 interacts with ATGL to regulate lipolysis and insulin sensitivity in human adipocytes. J. Biol. Chem. 2014. [CrossRef]

45. Ranjit, S.; Boutet, E.; Gandhi, P.; Prot, M.; Tamori, Y.; Chawla, A.; Greenberg, A.S.; Puri, V.; Czech, M.P. Regulation of fat specific protein 27 by isoproterenol and TNF- $\alpha$ to control lipolysis in murine adipocytes. J. Lipid Res. 2011, 52, 221-236. [CrossRef] [PubMed]

46. Singh, M.; Kaur, R.; Lee, M.-J.; Pickering, R.T.; Sharma, V.M.; Puri, V.; Kandror, K.V. Fat-specific Protein 27 Inhibits Lipolysis by Facilitating the Inhibitory Effect of Transcription Factor Egr1 on Transcription of Adipose Triglyceride Lipase. J. Biol. Chem. 2014, 289, 14481-14487. [CrossRef] [PubMed]

47. Singaravelu, R.; Lyn, R.K.; Srinivasan, P.; Delcorde, J.; Steenbergen, R.H.; Tyrrell, D.L.; Pezacki, J.P. Human serum activates CIDEB-mediated lipid droplet enlargement in hepatoma cells. Biochem. Biophys. Res. Commun. 2013, 441, 447-452. [CrossRef] [PubMed]

48. Qi, J.; Gong, J.; Zhao, T.; Zhao, J.; Lam, P.; Ye, J.; Li, J.Z.; Wu, J.; Zhou, H.-M.; Li, P. Downregulation of AMP-activated protein kinase by Cidea-mediated ubiquitination and degradation in brown adipose tissue. EMBO J. 2008, 27, 1537-1548. [CrossRef] [PubMed]

49. Viswakarma, N.; Yu, S.; Naik, S.; Kashireddy, P.; Matsumoto, K.; Sarkar, J.; Surapureddi, S.; Jia, Y.; Rao, M.S.; Reddy, J.K. Transcriptional regulation of Cidea, mitochondrial cell death-inducing DNA fragmentation factor alpha-like effector A, in mouse liver by peroxisome proliferator-activated receptor alpha and gamma. J. Biol. Chem. 2007, 282, 18613-18624. [CrossRef]

50. Osborne, T.F. Sterol Regulatory Element-binding Proteins (SREBPs): Key Regulators of Nutritional Homeostasis and Insulin Action. J. Biol. Chem. 2000, 275, 32379-32382. [CrossRef]

51. He, Q.; Diao, Y.; Zhao, T.; Hou, B.; Ngokana, L.D.; Liang, H.; Nie, J.; Tan, P.; Huang, H.; Li, Y.; et al. SREBP1c mediates the effect of acetaldehyde on Cidea expression in Alcoholic fatty liver Mice. Sci. Rep. 2018, 8, 1200. [CrossRef] [PubMed]

52. Shimabukuro, M.; Zhou, Y.-T.; Levi, M.; Unger, R.H. Fatty acid-induced $\beta$ cell apoptosis: A link between obesity and diabetes. Proc. Natl. Acad. Sci. USA 1998, 95, 2498-2502. [CrossRef] [PubMed]

53. Omae, N.; Ito, M.; Hase, S.; Nagasawa, M.; Ishiyama, J.; Ide, T.; Murakami, K. Suppression of FoxO1/cell death-inducing DNA fragmentation factor $\alpha$-like effector A (Cidea) axis protects mouse $\beta$-cells against palmitic acid-induced apoptosis. Mol. Cell. Endocrinol. 2012, 348, 297-304. [CrossRef] [PubMed] 
54. Zhang, S.; Shui, G.; Wang, G.; Wang, C.; Sun, S.; Zouboulis, C.C.; Xiao, R.; Ye, J.; Li, W.; Li, P. Cidea control of lipid storage and secretion in mouse and human sebaceous glands. Mol. Cell. Biol. 2014, 34, 1827-1838. [CrossRef] [PubMed]

55. Wang, W.; Lv, N.; Zhang, S.; Shui, G.; Qian, H.; Zhang, J.; Chen, Y.; Ye, J.; Xie, Y.; Shen, Y.; et al. Cidea is an essential transcriptional coactivator regulating mammary gland secretion of milk lipids. Nat. Med. 2012, 18, 235-243. [CrossRef]

56. Sun, C.; Zhao, Y.; Gao, X.; Yuan, Y.; Wang, C.; Wang, Y.; Zhang, L.; Gu, Y.; Zhang, F.; Hu, P.; et al. Cideb Deficiency Aggravates Dextran Sulfate Sodium-induced Ulcerative Colitis in Mice by Exacerbating the Oxidative Burden in Colonic Mucosa. Inflamm. Bowel Dis. 2017, 23, 1338-1347. [CrossRef]

57. Langhi, C.; Arias, N.; Rajamoorthi, A.; Basta, J.; Lee, R.G.; Baldán, Á. Therapeutic silencing of fat-specific protein 27 improves glycemic control in mouse models of obesity and insulin resistance. J. Lipid Res. 2017, 58, 81-91. [CrossRef]

58. Tanaka, N.; Takahashi, S.; Matsubara, T.; Jiang, C.; Sakamoto, W.; Chanturiya, T.; Teng, R.; Gavrilova, O.; Gonzalez, F.J. Adipocyte-specific disruption of fat-specific protein 27 causes hepatosteatosis and insulin resistance in high-fat diet-fed mice. J. Biol. Chem. 2015, 290, 3092-3105. [CrossRef]

59. Bermúdez, V.; Finol, F.; Parra, N.; Parra, M.; Pérez, A.; Peñaranda, L.; Vílchez, D.; Rojas, J.; Arráiz, N.; Velasco, M. PPAR-gamma agonists and their role in type 2 diabetes mellitus management. Am. J. Ther. 2010, 17, 274-283. [CrossRef]

60. Bedoucha, M.; Atzpodien, E.; Boelsterli, U.A. Diabetic KKAy mice exhibit increased hepatic PPARgamma1 gene expression and develop hepatic steatosis upon chronic treatment with antidiabetic thiazolidinediones. J. Hepatol. 2001, 35, 17-23. [CrossRef]

61. Matsusue, K.; Kusakabe, T.; Noguchi, T.; Takiguchi, S.; Suzuki, T.; Yamano, S.; Gonzalez, F.J. Hepatic steatosis in leptin-deficient mice is promoted by the PPARgamma target gene Fsp27. Cell Metab. 2008, 7, 302-311. [CrossRef] [PubMed]

62. Xu, M.-J.; Cai, Y.; Wang, H.; Altamirano, J.; Chang, B.; Bertola, A.; Odena, G.; Lu, J.; Tanaka, N.; Matsusue, K.; et al. Fat-Specific Protein 27/CIDEC Promotes Development of Alcoholic Steatohepatitis in Mice and Humans. Gastroenterology 2015, 149, 1030.e6-1041.e6. [CrossRef] [PubMed]

63. Vilà-Brau, A.; De Sousa-Coelho, A.L.; Gonçalves, J.F.; Haro, D.; Marrero, P.F. Fsp27/CIDEC is a CREB target gene induced during early fasting in liver and regulated by FA oxidation rate. J. Lipid Res. 2013, 54, 592-601. [CrossRef] [PubMed]

64. Lee, S.W.; Rho, J.H.; Lee, S.Y.; Chung, W.T.; Oh, Y.J.; Kim, J.H.; Yoo, S.H.; Kwon, W.Y.; Bae, J.Y.; Seo, S.Y.; et al. Dietary fat-associated osteoarthritic chondrocytes gain resistance to lipotoxicity through PKCK2/STAMP2/FSP27. Bone Res. 2018, 6, 20. [CrossRef] [PubMed]

65. Zhou, L.; Park, S.-Y.; Xu, L.; Xia, X.; Ye, J.; Su, L.; Jeong, K.-H.; Hur, J.H.; Oh, H.; Tamori, Y.; et al. Insulin resistance and white adipose tissue inflammation are uncoupled in energetically challenged Fsp27-deficient mice. Nat. Commun. 2015, 6, 5949. [CrossRef]

66. Chen, W.; Li, S.; Cook, N.R.; Rosner, B.A.; Srinivasan, S.R.; Boerwinkle, E.; Berenson, G.S. An autosomal genome scan for loci influencing longitudinal burden of body mass index from childhood to young adulthood in white sibships: The Bogalusa Heart Study. Int. J. Obes. Relat. Metab. Disord. J. Int. Assoc. Study Obes. 2004, 28, 462-469. [CrossRef]

67. Parker, A.; Meyer, J.; Lewitzky, S.; Rennich, J.S.; Chan, G.; Thomas, J.D.; Orho-Melander, M.; Lehtovirta, M.; Forsblom, C.; Hyrkkö, A.; et al. A gene conferring susceptibility to type 2 diabetes in conjunction with obesity is located on chromosome 18p11. Diabetes 2001, 50, 675-680. [CrossRef]

68. Dahlman, I.; Kaaman, M.; Jiao, H.; Kere, J.; Laakso, M.; Arner, P. The CIDEA gene V115F polymorphism is associated with obesity in Swedish subjects. Diabetes 2005, 54, 3032-3034. [CrossRef]

69. Zhang, L.; Miyaki, K.; Nakayama, T.; Muramatsu, M. Cell death-inducing DNA fragmentation factor alpha-like effector A (CIDEA) gene V115F (G->T) polymorphism is associated with phenotypes of metabolic syndrome in Japanese men. Metabolism. 2008, 57, 502-505. [CrossRef]

70. Wu, J.; Zhang, L.; Zhang, J.; Dai, Y.; Bian, L.; Song, M.; Russell, A.; Wang, W. The genetic contribution of CIDEA polymorphisms, haplotypes and loci interaction to obesity in a Han Chinese population. Mol. Biol. Rep. 2013, 40, 5691-5699. [CrossRef] 
71. Johansson, L.E.; Danielsson, A.P.H.; Parikh, H.; Klintenberg, M.; Norström, F.; Groop, L.; Ridderstråle, M. Differential gene expression in adipose tissue from obese human subjects during weight loss and weight maintenance. Am. J. Clin. Nutr. 2012, 96, 196-207. [CrossRef] [PubMed]

72. Montastier, E.; Déjean, S.; Gall, C.L.; Saris, W.H.M.; Langin, D.; Viguerie, N. Adipose Tissue CIDEA Is Associated, Independently of Weight Variation, to Change in Insulin Resistance during a Longitudinal Weight Control Dietary Program in Obese Individuals. PLoS ONE 2014, 9, e98707. [CrossRef] [PubMed]

73. Tan, X.; Cao, Z.; Li, M.; Xu, E.; Wang, J.; Xiao, Y. TNF- $\alpha$ downregulates CIDEC via MEK/ERK pathway in human adipocytes. Obesity 2016, 24, 1070-1080. [CrossRef]

74. Moreno-Navarrete, J.M.; Ortega, F.; Serrano, M.; Rodriguez-Hermosa, J.I.; Ricart, W.; Mingrone, G.; Fernández-Real, J.M. CIDEC/FSP27 and PLIN1 gene expression run in parallel to mitochondrial genes in human adipose tissue, both increasing after weight loss. Int. J. Obes. 2014, 38, 865-872. [CrossRef]

75. Greenberg, A.S.; Coleman, R.A.; Kraemer, F.B.; McManaman, J.L.; Obin, M.S.; Puri, V.; Yan, Q.-W.; Miyoshi, H.; Mashek, D.G. The role of lipid droplets in metabolic disease in rodents and humans. J. Clin. Investig. 2011, 121, 2102-2110. [CrossRef]

76. Sharma, V.M.; Vestergaard, E.T.; Jessen, N.; Kolind-Thomsen, P.; Nellemann, B.; Nielsen, T.S.; Vendelbo, M.H.; Møller, N.; Sharma, R.; Lee, K.Y.; et al. Growth hormone acts along the PPAR $\gamma$-FSP27 axis to stimulate lipolysis in human adipocytes. Am. J. Physiol. Endocrinol. Metab. 2018, 316, E34-E42. [CrossRef] [PubMed]

77. Banks, A.S.; McAllister, F.E.; Camporez, J.P.G.; Zushin, P.-J.H.; Jurczak, M.J.; Laznik-Bogoslavski, D.; Shulman, G.I.; Gygi, S.P.; Spiegelman, B.M. An ERK/Cdk5 axis controls the diabetogenic actions of PPAR $\gamma$. Nature 2015, 517, 391-395. [CrossRef] [PubMed]

78. Choi, J.H.; Banks, A.S.; Estall, J.L.; Kajimura, S.; Boström, P.; Laznik, D.; Ruas, J.L.; Chalmers, M.J.; Kamenecka, T.M.; Blüher, M.; et al. Anti-diabetic drugs inhibit obesity-linked phosphorylation of PPARgamma by Cdk5. Nature 2010, 466, 451-456. [CrossRef] [PubMed]

79. Li, P.; Fan, W.; Xu, J.; Lu, M.; Yamamoto, H.; Auwerx, J.; Sears, D.D.; Talukdar, S.; Oh, D.; Chen, A.; et al. Adipocyte NCoR knockout decreases PPAR $\gamma$ phosphorylation and enhances PPAR $\gamma$ activity and insulin sensitivity. Cell 2011, 147, 815-826. [CrossRef]

80. Sharma, R.; Luong, Q.; Sharma, V.M.; Harberson, M.; Harper, B.; Colborn, A.; Berryman, D.E.; Jessen, N.; Jørgensen, J.O.L.; Kopchick, J.J.; et al. Growth hormone controls lipolysis by regulation of FSP27 expression. J. Endocrinol. 2018, 239, 289-301. [CrossRef] 